\title{
Attitudes of Czech Drivers to Issue of Drinking and Driving - Development in Time and International Comparisons
}

\author{
P. Skládaná*, E. Drápela, A. Zaoral \\ Department of Road Safety, Transport Research Centre, Brno, Czech Republic \\ * Corresponding author: pavlina.skladana@cdv.cz
}

DOI: 10.2478/trans-2014-0003

\begin{abstract}
This study deals with attitudes of Czech drivers to the issues of drinking and driving, on the basis of SARTRE (Social Attitudes to Road Traffic Risk in Europe) surveys carried out during 1991 - 2002 in European countries. The results of the Czech part of SARTRE 4 show that drivers in the Czech Republic maintain their support to tightening of sanctions against drinking and driving and support, more than ever before, the technical measures which prevent drinking and driving. In general, they stand against drinking and driving and, based on their words, they rarely violate the drinking and driving regulations concerning even the slightest amount of alcohol. On the other hand, the support for increasing the maximum legal alcohol level in blood has increased and the extent of this support is also higher in the international comparison. A positive feature is the increased level of experience with the enforcement of drinking and driving regulations and the resulting increased perceived probability of being checked when driving.
\end{abstract}

KEY WORDS: Road safety, drink driving, car drivers.

\section{INTRODUCTION AND METHOD}

SARTRE (Social Attitudes to Road Traffic Risk in Europe) is an international comparative project that maps the attitudes of European road users to the most important aspects of road safety (speed, seat belts, alcohol and drugs, fatigue, style of driving, legislation and control, causes of traffic accidents, importance of road safety in relation to other social issues) using a uniform methodology in every participating country. Four SARTRE surveys have been carried out until now - SARTRE 1, including 15 countries, in 1991, SARTRE 2, including 19 countries, in 1996, SARTRE 3 with 23 countries in 2002 and 2012, SARTRE 4 was completed, including 19 European countries. The Czech Republic participated in all four surveys.

While in the previous surveys only car drivers were considered, SARTRE 4 also deals with the views expressed by motorcyclists and other road users (pedestrians, cyclists). The Czech sample (similarly to samples of other countries) includes 1002 respondents, out of which 600 were car drivers, 202 motorcyclists, and 200 pedestrians and cyclists. The groups of motorcyclists and other road users are deliberately overrepresented to achieve statistical confidence in the analyses (Cestac et al., 2012).

The decisive phase of the project, a questionnaire survey, was carried out at the end of 2010. The method of quota sampling by age, sex and occupation of the basic set (road users over eighteen years of age) gave a sample of respondents who, in face-to-face interviews, answered questions put in an extensive standardized questionnaire. 
Using the SARTRE data, we address in this study the attitudes of the group of Czech car drivers to the issues of drunk driving. The attitudes of Czech car drivers expressed in SARTRE 4 interviews are compared with attitudes of drivers from other participating countries, and with data from previous SARTRE researches.

The range of the questions included in the SARTRE questionnaire enables complex description of drinking and driving problem from road users' point of view. The respondents were asked to express their agreement or disagreement with several statements related to driving under the influence of alcohol, and then they were asked specifically to their behaviour in this regard. They also expressed their views on the maximum permitted level of alcohol in blood and police BAC checks.

However, the issue of drink driving is one of the most difficult in terms of international comparisons, because the legal maximum blood alcohol levels differ across Europe and a simple comparison could be misleading, so we mention them only where it makes sense (and where the position of the Czech Republic in the international context is in some way interesting). The opportunity to compare views of drivers over time is also somewhat limited because some questions were not asked in past projects or were phrased differently. A substantial part of the output, however, can be compared.

\section{SUPPORT OF MEASURES AGAINST DRINK DRIVING}

At the beginning of the interview, respondents were asked whether they would consider beneficial certain devices or measures to prevent drink driving.

2.1 "Alcolocks" to prevent the driver from driving if over the legal alcohol limit (for all drivers)

Table 1: Opinion of Czech drivers on the benefits of alcohol interlocks required for all.

\begin{tabular}{|l|l|l|l|l|}
\hline & Very & Rather yes & Rather no & Not at all \\
\hline 1996 & $23.3 \%$ & $76.7 \%$ & \multicolumn{2}{|l|}{} \\
\hline 2002 & $37.5 \%$ & $62.5 \%$ & $\mathbf{8 . 0} \%$ \\
\hline 2010 & $\mathbf{4 0 . 8 \%}$ & $\mathbf{3 4 . 8 \%}$ & $\mathbf{1 6 . 4 \%}$ & \\
\hline
\end{tabular}

Compared with the previous surveys (Skládaná et al., 2005), there was a significant shift in the attitudes of Czech drivers towards this device. While in 1996 only 23.3\% of drivers considered alcohol interlocks beneficial, in 2002 their proportion increased to $37.5 \%$ and in the last survey, drivers in support to this technology prevailed significantly $-75.6 \%$ in total. The level of their agreement is not much affected by the question if the device would be required for all or only for those who have already had problems with alcohol (see Chapter 2.2).

2.2 "Alcolocks" only for drivers who have already violated drinking and driving regulations

Table 2: Opinion of Czech drivers on the usefulness of alcohol interlocks for drivers who have already had problems with alcohol.

\begin{tabular}{|l|l|l|l|}
\hline Very & Rather yes & Rather no & Not at all \\
\hline $\mathbf{4 6 . 8} \%$ & $\mathbf{2 9 . 3 \%}$ & $\mathbf{1 6 . 4 \%}$ & $\mathbf{7 . 5 \%}$ \\
\hline
\end{tabular}


2.3 More severe penalties for driving under the influence of alcohol

Table 3: Opinion of Czech drivers on more severe penalties for driving under the influence of alcohol.

\begin{tabular}{|l|l|l|l|l|l|}
\hline & Fully agree & Fairly & Undecided & Rather disagree & Absolutely disagree \\
\hline 2002 & $90 \%$ & $6.2 \%$ & $3.8 \%$ & \\
\hline 2010 & $\mathbf{6 0 . 7 \%}$ & $\mathbf{2 6 . 9 \%}$ & $\mathbf{8 . 0 \%}$ & $\mathbf{2 . 2 \%}$ & $\mathbf{2 . 2 \%}$ \\
\hline
\end{tabular}

This question has already been asked in the SARTRE 3 project (Cauzard et al., 2004). The proportion of agreement and disagreement responses remained practically unchanged, the vast majority of drivers generally supports more severe penalties for driving under the influence of alcohol.

\section{ATTITUDES TOWARDS DRIVING UNDER INFLUENCE OF ALCOHOL}

Respondents were given four statements that could be classified in a four-point rating scale according to the level of their agreement from "very" to "not at all".

\subsection{You can drink and drive if you drive carefully}

With the first statement, "You can drive under the influence of alcohol if you drive carefully", only $8.8 \%$ of drivers surveyed agreed, mostly only partially. Majority of respondents tended to disagree, $72.3 \%$ of the respondents disagreed at all. As expected according to previous research experiences (Baum, 2000; Cauzard et al., 2004; Skládaná et al., 2005), the results differed by gender. Females refused this statement more often than males $(87.4 \%$ of males vs. $96.1 \%$ of females).

Table 4: Level of agreement among Czech drivers with the statement "You can drive under the influence of alcohol if you drive carefully”.

\begin{tabular}{|l|l|}
\hline Very & $\mathbf{0 . 8 \%}$ \\
\hline Fairly & $\mathbf{8 . 0 \%}$ \\
\hline Not much & $\mathbf{1 8 . 8 \%}$ \\
\hline Not at all & $\mathbf{7 2 . 3 \%}$ \\
\hline
\end{tabular}

3.2 Driving under the influence of alcohol increases the risk of conflict with other road users

On the other hand, most drivers agreed with the phrase "Driving under the influence of alcohol increases the risk of conflict with other road users" that was declined only by $8.5 \%$ of the respondents. Males and females agreed to the same extent, females just more inclined to the stronger form of consent; and there are no significant differences between the age groups. 
Table 5: Level of agreement among Czech drivers with the statement "Driving under the influence of alcohol increases the risk of conflict with other road users".

\begin{tabular}{|l|l|}
\hline Very & $\mathbf{6 6 . 3 \%}$ \\
\hline Fairly & $\mathbf{2 5 . 2 \%}$ \\
\hline Not much & $\mathbf{2 . 7 \%}$ \\
\hline Not at all & $\mathbf{5 . 8 \%}$ \\
\hline
\end{tabular}

3.3 If you drive under the influence of alcohol, you will be checked and fined by the police

As for the statement "If you drive under the influence of alcohol, you will be checked and fined by the police" agreements prevailed, but respondents chose mostly less decisive forms of their consent or disagreement. Females agreed only slightly more often than males (75.5\% of females, $71.4 \%$ of males). Among the age groups, the group of $35-44$ years of age differs; their disagreement with the statement (34.8\%) is significantly more frequent compared to the rest of sample. On the contrary, in the age group of $45-54$, the disagreement is less frequent (17.9\%).

Table 6: Level of agreement among Czech drivers with the statement "If you drive under the influence of alcohol, you will be checked and fined by the police".

\begin{tabular}{|l|l|}
\hline Very & $\mathbf{2 4 . 3 \%}$ \\
\hline Fairly & $\mathbf{4 8 . 8 \%}$ \\
\hline Not much & $\mathbf{2 0 . 8 \%}$ \\
\hline Not at all & $\mathbf{6 . 0 \%}$ \\
\hline
\end{tabular}

\subsection{Most of your friends would drive under the influence of alcohol}

The statement "Most of your friends would drive under the influence of alcohol" is phrased less generally than the previous statements and has usually been met with disagreement (93.1\%), but not always decisive, $49.3 \%$ of the respondents chose the more cautious form "not much". Females are somewhat clearer in this case again (48.2\% of females vs. $40.5 \%$ of males "Not at all"). What is worthy of note, however, is the difference between the lowest and highest age category (see Table 8). It is obvious that on the concrete level, drinking and driving is less tabooed in the youngest generation than among senior drivers. In an international comparison (Cestac et al., 2012) however, together with Sweden, Finland, Hungary and Ireland we are still among to the countries with the lowest proportion of respondents who expressed agreement with that statement.

Table 7: Level of agreement among Czech drivers with the statement "Most of your friends would drive under the influence of alcohol”.

\begin{tabular}{|l|l|}
\hline Very & $1.3 \%$ \\
\hline Fairly & $5.5 \%$ \\
\hline Not much & $49.3 \%$ \\
\hline Not at all & $\mathbf{4 3 . 8 \%}$ \\
\hline
\end{tabular}


Table 8: Level of agreement among Czech drivers with the statement "Most of your friends would drive under the influence of alcohol" according to the age of respondents.

\begin{tabular}{|l|l|l|l|l|}
\hline & Very & Rather yes & Rather no & Not at all \\
\hline $18-24$ & $\mathbf{1 . 4 \%}$ & $\mathbf{9 . 7 \%}$ & $\mathbf{5 2 . 8 \%}$ & $\mathbf{3 6 . 1 \%}$ \\
\hline $65+$ & $\mathbf{0 . 0 \%}$ & $\mathbf{0 . 0 \%}$ & $\mathbf{4 6 . 9 \%}$ & $\mathbf{5 3 . 1 \%}$ \\
\hline
\end{tabular}

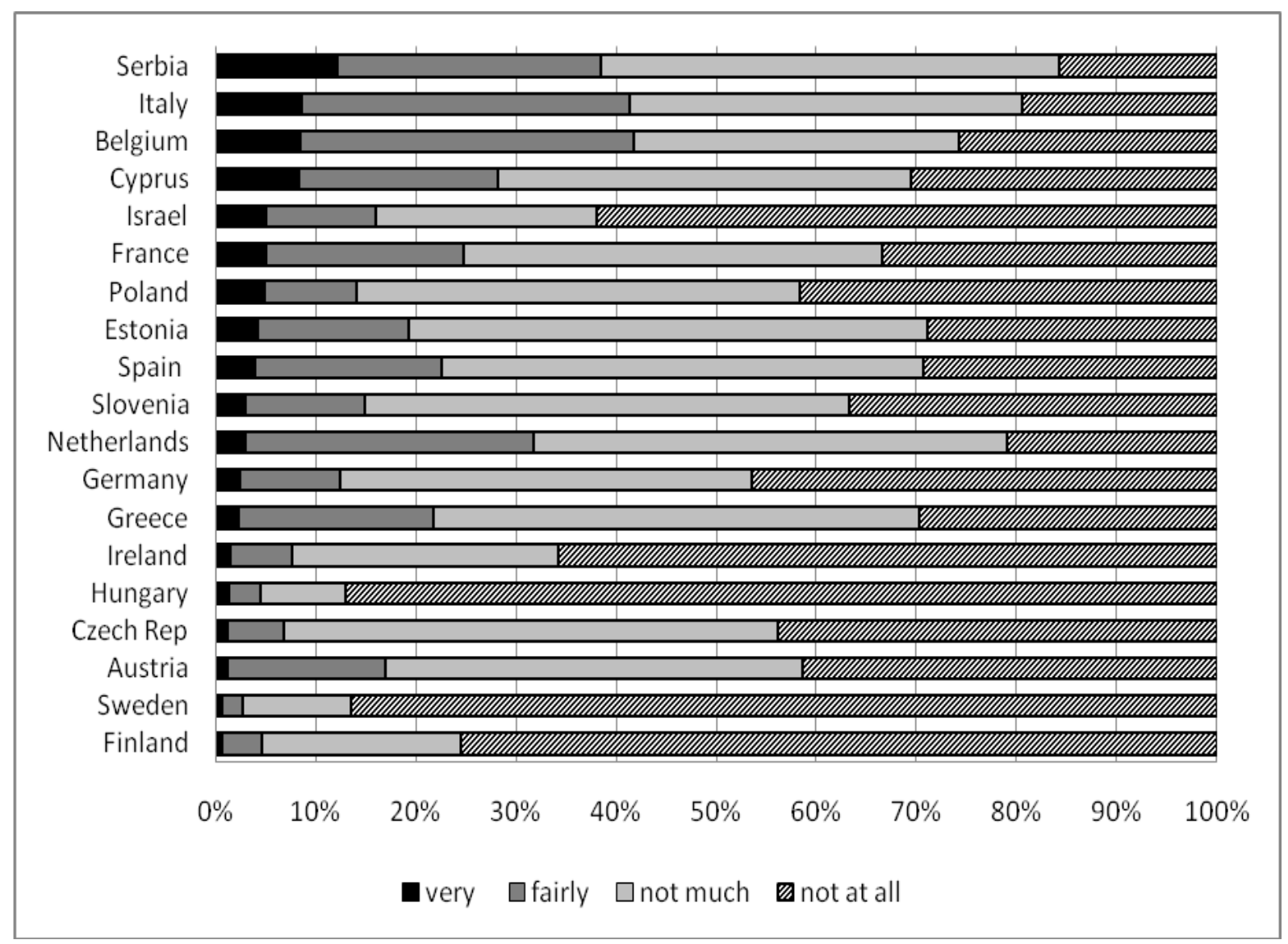

Figure 1: Level of agreement with the statement "Most of your friends would drive under the influence of alcohol”, international comparison.

\section{BEHAVIOUR OF DRIVERS IN RELATION TO DRINKING AND DRIVING}

In the next block, drivers were asked about their own behaviour in relation to driving under the influence of alcohol. The first question was about drinking even a small amount of alcohol before driving over the last month - generally, such an amount of alcohol that should not cause exceeding the legal limit of alcohol in the driver's blood (in fact or in the driver's opinion); the second question related to drinking of such an amount of alcohol, which may cause the exceeding of the limit. This, however, in countries with a limit of $0.0 \mathrm{~g} / \mathrm{l}$, as the Czech Republic, means something different than in countries with the permitted level of $0.2-0.5 \mathrm{~g} / \mathrm{l}$. Therefore, international comparison is not of great explanatory value here, and for this reason, it is not mentioned in this chapter. 
4.1 Over the last month, how often have you driven a car after having drunk even a small amount of alcohol?

Among the respondents, $86.3 \%$ of them answered this question as "never", $11 \%$ "seldom". The answer "never" was more often used by females and all respondents of the age group of 65+ (over 90\% also in the age groups of 18 - 24 and 45 - 54). Answers "sometimes", "often" and "very often" were chosen only rarely; they do not occur significantly often in any age or gender category.

Table 9: Frequency of consumption of a small amount of alcohol before driving among Czech drivers.

\begin{tabular}{|l|l|}
\hline Never & $\mathbf{8 6 . 3 \%}$ \\
\hline Seldom & $\mathbf{1 1 . 0 \%}$ \\
\hline Sometimes & $\mathbf{1 . 5 \%}$ \\
\hline Often & $\mathbf{0 . 7 \%}$ \\
\hline Very often & $\mathbf{0 . 5 \%}$ \\
\hline
\end{tabular}

4.2 Over the last month, how often did you drive a car, when you may have been over the legal limit for drinking and driving for the Czech Republic, a "zero tolerance"?

Considering the legal limit $0.0 \mathrm{~g} / \mathrm{l}$, it is not surprising that in the Czech sample the question specifically concerning the amount of alcohol, when the limit may have been exceeded, was answered practically the same as the previous question, also with respect to age and gender.

Table 10: Frequency of driving after possibly drinking alcohol over the limit among Czech drivers.

\begin{tabular}{|l|l|}
\hline Never & $\mathbf{8 7 . 8 \%}$ \\
\hline Seldom & $\mathbf{1 0 . 0 \%}$ \\
\hline Sometimes & $\mathbf{1 . 5 \%}$ \\
\hline Often & $\mathbf{0 . 2 \%}$ \\
\hline Very often & $\mathbf{0 . 5 \%}$ \\
\hline
\end{tabular}

\section{MAXIMUM LEGAL BLOOD ALCOHOL LEVEL}

Drivers were also asked two questions about the permitted levels of alcohol. The first one examined respondents' opinion on how much alcohol they can drink before driving. Answers were reported in fixed units, where one unit matched to the amount of alcoholic beverage containing about $10 \mathrm{~g}$ of alcohol - for example a small glass of beer or a decilitre of wine. The second question concerned the drivers' opinions on what should the limit be.

5.1 In your opinion, how much alcohol can we drink before driving and still remain under the legal limit, a "zero tolerance"?

Almost three quarters of the respondents reported that to comply with the limit of $0.0 \mathrm{~g} / \mathrm{l}$ they cannot drink any alcohol, and $21.8 \%$ reported one unit. There is a significant difference between males and females, more females than males reported zero option $(82.1 \%$ versus $67.3 \%$ ) while $7.0 \%$ of males in comparison with $0.8 \%$ of females believed that they can drink 
up to two units of alcohol. Age does not play very significant role, only in the age group of $65^{+}$, there is no respondent indicating more than one unit, and $84.4 \%$ does not accept any alcoholic beverage. In comparison with 2002 (Skládaná et al., 2005), there is a drop by $11 \%$ in the proportion of the respondents who believe that to comply with the legal limit they can not drink any alcoholic beverage.

Table 11: Opinions of Czech drivers on amount of alcoholic beverages that driver can drink and still remain under the legal limit, in units.

\begin{tabular}{|l|l|}
\hline 0 & $\mathbf{7 3 . 7 \%}$ \\
\hline 1 & $\mathbf{2 1 . 8 \%}$ \\
\hline 2 & $\mathbf{4 . 3 \%}$ \\
\hline 3 & $\mathbf{0 . 2 \%}$ \\
\hline
\end{tabular}

5.2 What should be the legal limit for alcohol in blood?

Maintaining the current legislation, i.e. the limit of $0.0 \mathrm{~g} / \mathrm{l}$, was supported by $78.4 \%$ of the respondents; $21.4 \%$ would increase the limit. One single respondent was for an unlimited consumption of alcohol before driving. In comparison with the previous SARTRE surveys (Skládaná et al., 2005), the rate of those who support the limit increase rose from $14.4 \%$ in 1996 and $13.6 \%$ in 2002 to $21.4 \%$. The supporters of higher limit can be found rather among males (26.7\%) and in the age group of 35 - 44 (29.3\%).

In international comparison (Cestac et al., 2012), the Czech Republic is now a country with the highest rate of those who support the current limit increase, even compared to countries that have legalized very low level of alcohol (Sweden, Estonia, Poland, Serbia) or also $0.0 \mathrm{~g} / \mathrm{l}$ (Hungary). Despite recent tightening up the penalties for drunk driving in these countries, we can find high support to the existing regulations in Hungary, and over 90\% drivers supporting establishing of the limit of $0.0 \mathrm{~g} / \mathrm{l}$ in Estonia and Poland. In order the Czech Republic does not take the course against the European trend towards reducing the alcohol limit, it would probably be appropriate to make steps to renew the support to the existing legislation.

Table 12: Support of the existing maximum permitted level of alcohol in blood before driving among Czech drivers.

\begin{tabular}{|l|l|l|l|}
\hline & 2010 & 2002 & 1996 \\
\hline Current state & $\mathbf{7 8 . 4 \%}$ & $\mathbf{8 4 . 6 \%}$ & $\mathbf{8 2 . 4 \%}$ \\
\hline Higher permitted level & $\mathbf{2 1 . 4 \%}$ & $\mathbf{1 3 . 6 \%}$ & $\mathbf{1 4 . 4 \%}$ \\
\hline Any amount of alcohol & $\mathbf{0 . 2 \%}$ & $\mathbf{1 . 8 \%}$ & $\mathbf{3 . 2 \%}$ \\
\hline
\end{tabular}




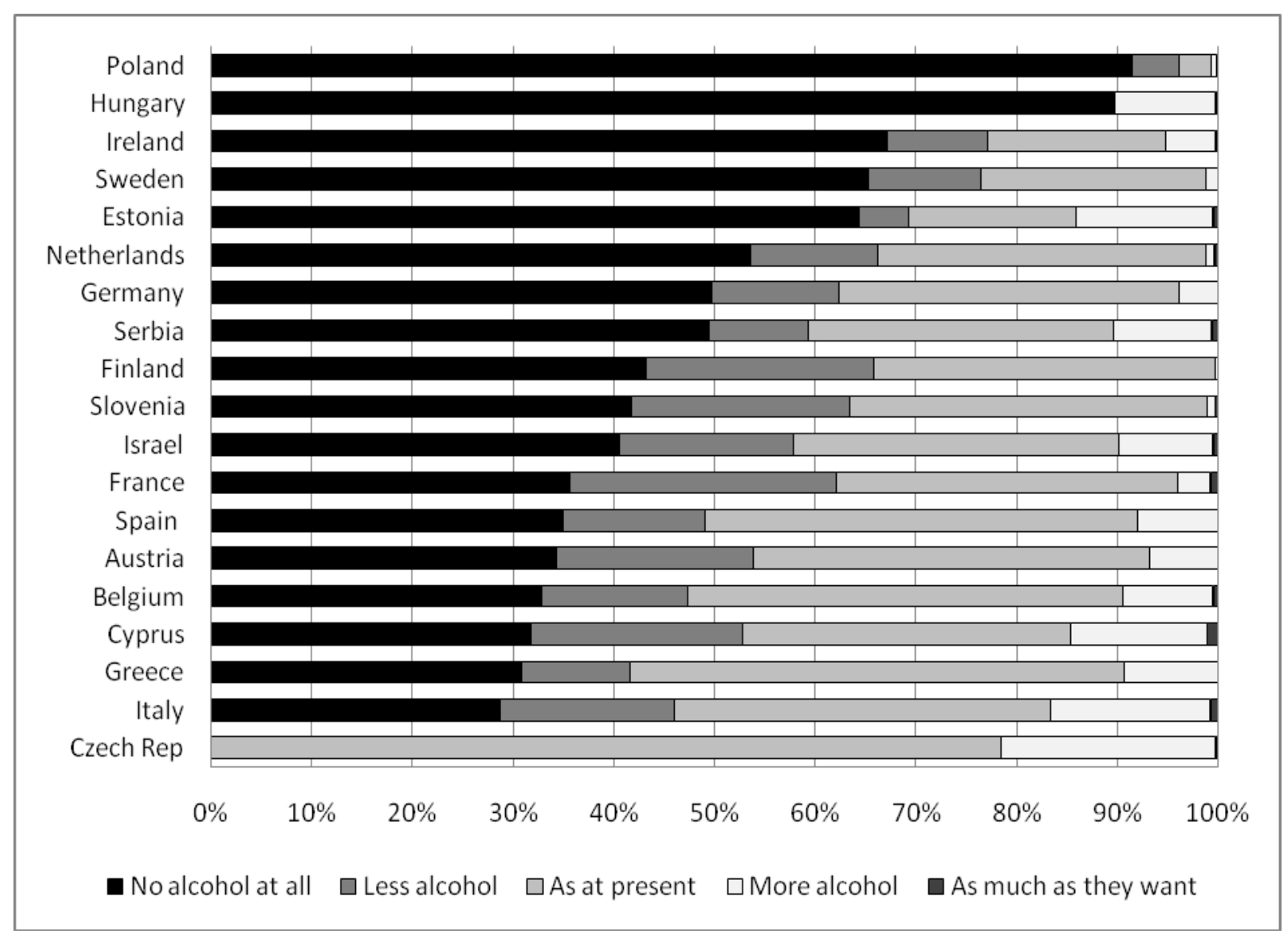

Figure 2: Support to the current maximum permitted level of alcohol in blood before driving, international comparison.

\section{POLICE ENFORCEMENT}

Two questions related to checks for alcohol behind the wheel by the police - its frequency and odds of occurrence on a typical car journey.

6.1 In the past 3 years, how many times have you been checked for alcohol while driving a car?

The largest proportion of the respondents, $42.2 \%$, reported that within the past three years they have not been checked by police. $31.8 \%$ of drivers were checked once and $26 \%$ more than once. The likelihood of being checked naturally rises with increasing driving performance. Compared to the last SARTRE survey results (Skládaná et al., 2005) there was a significant (by 26\%) drop in the proportion of respondents who have not been checked for alcohol over the past three years, and also in an international comparison (Cestac et al., 2012), the Czech Republic ranges among countries with the lowest proportion of drivers who have not been checked.

Table 13: Experience of Czech drivers with checks by the police in the past three years.

\begin{tabular}{|l|l|l|}
\hline & $\mathbf{2 0 1 0}$ & $\mathbf{2 0 0 2}$ \\
\hline Never & $\mathbf{4 2 . 2 \%}$ & $\mathbf{6 8 . 3 \%}$ \\
\hline Only once & $\mathbf{3 1 . 8 \%}$ & $\mathbf{1 9 . 8 \%}$ \\
\hline More than once & $\mathbf{2 6 . 0 \%}$ & $\mathbf{1 1 . 9 \%}$ \\
\hline
\end{tabular}




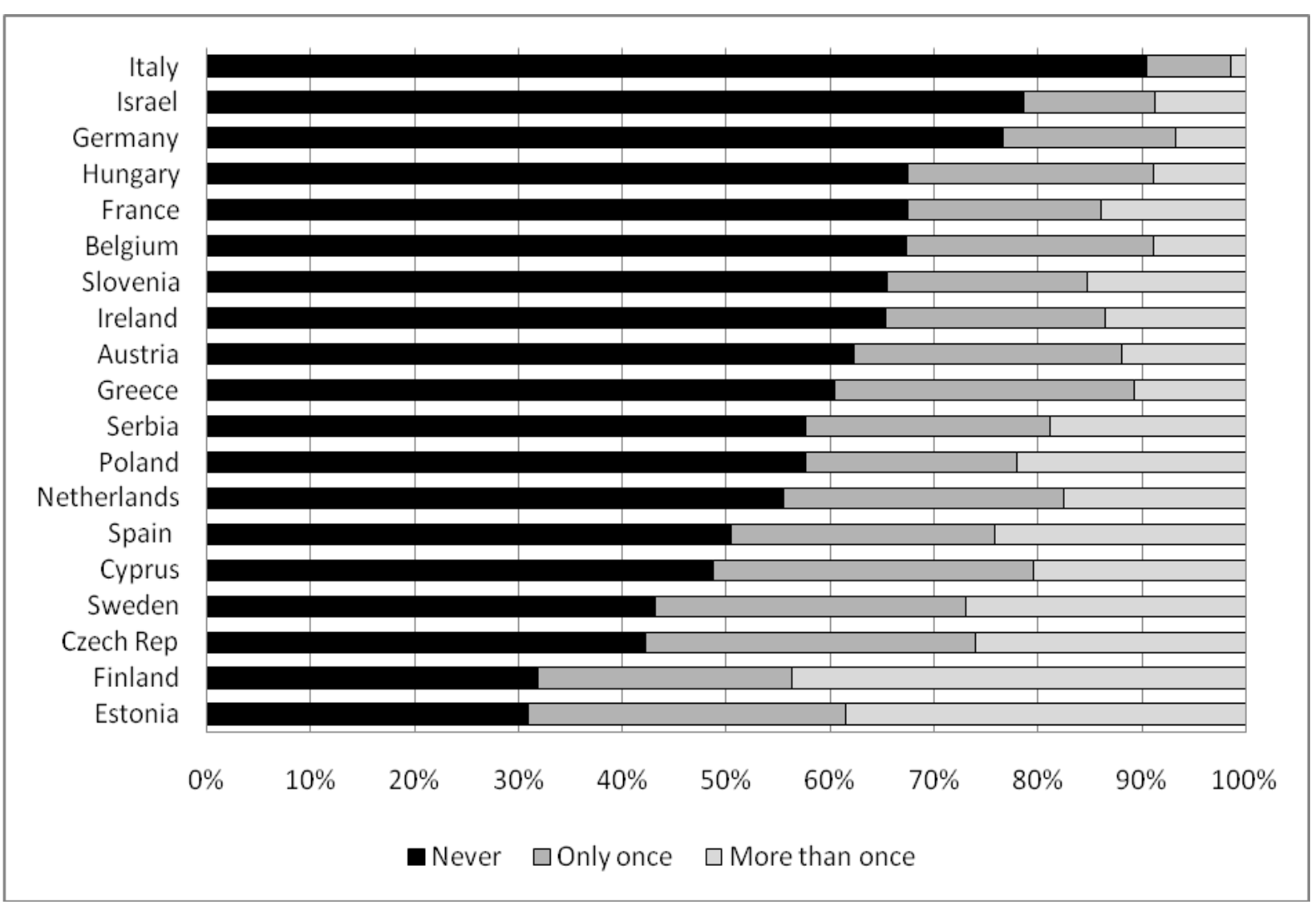

Figure 3: Experience with police check over the past three years, international comparison.

6.2 In your opinion, on your typical car journey, how likely is it that you will be checked for alcohol?

In terms of the effectiveness of police enforcement, the expectation of drivers that they will be checked - so called subjective risk - plays an important role together with actual frequency of checks. It can be said that according to the results of the survey, the expectations very closely reflect the factual experience of respondents (Table 15). In comparison with the previous surveys (Skládaná et al., 2005), the proportion of those who expect to be checked sometimes or often during their journey increased. In an international comparison (Cestac et al., 2012), Czech drivers mostly expect to be checked sometimes or often.

Table 14: Perceived probability of being checked for alcohol among Czech drivers.

\begin{tabular}{|l|l|l|l|}
\hline & 2010 & 2002 & 1996 \\
\hline Never & $13.2 \%$ & $12.4 \%$ & $12.2 \%$ \\
\hline Rarely & $33.8 \%$ & $50.3 \%$ & $60.9 \%$ \\
\hline Sometimes & $33.3 \%$ & $24.4 \%$ & $20.3 \%$ \\
\hline Often & $\mathbf{1 2 . 3 \%}$ & $5.9 \%$ & $3.6 \%$ \\
\hline Very often & $\mathbf{3 . 3 \%}$ & $\mathbf{4 . 0 \%}$ & $\mathbf{1 . 9 \%}$ \\
\hline Always & $\mathbf{4 . 0 \%}$ & $\mathbf{3 . 0 \%}$ & $\mathbf{1 . 1 \%}$ \\
\hline
\end{tabular}


Table 15: Perceived probability of being checked for alcohol according to frequency of checks over the past three years among Czech drivers.

\begin{tabular}{|c|c|c|c|c|c|c|c|}
\hline & \multicolumn{6}{|c|}{ Likelihood of check } \\
\hline & & Never & Rarely & Sometimes & Often & $\begin{array}{l}\text { Very } \\
\text { often }\end{array}$ & Always \\
\hline \multirow{3}{*}{ 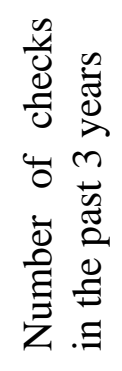 } & Never & $26.9 \%$ & $39.9 \%$ & $24.1 \%$ & $4.0 \%$ & $1.6 \%$ & $3.6 \%$ \\
\hline & $\begin{array}{l}\text { Only } \\
\text { once }\end{array}$ & $3.1 \%$ & $42.9 \%$ & $37.2 \%$ & $10.5 \%$ & $1.6 \%$ & $4.7 \%$ \\
\hline & $\begin{array}{l}\text { More } \\
\text { than } \\
\text { once }\end{array}$ & $3.2 \%$ & $12.8 \%$ & $43.6 \%$ & $28.2 \%$ & $8.3 \%$ & $3.8 \%$ \\
\hline
\end{tabular}

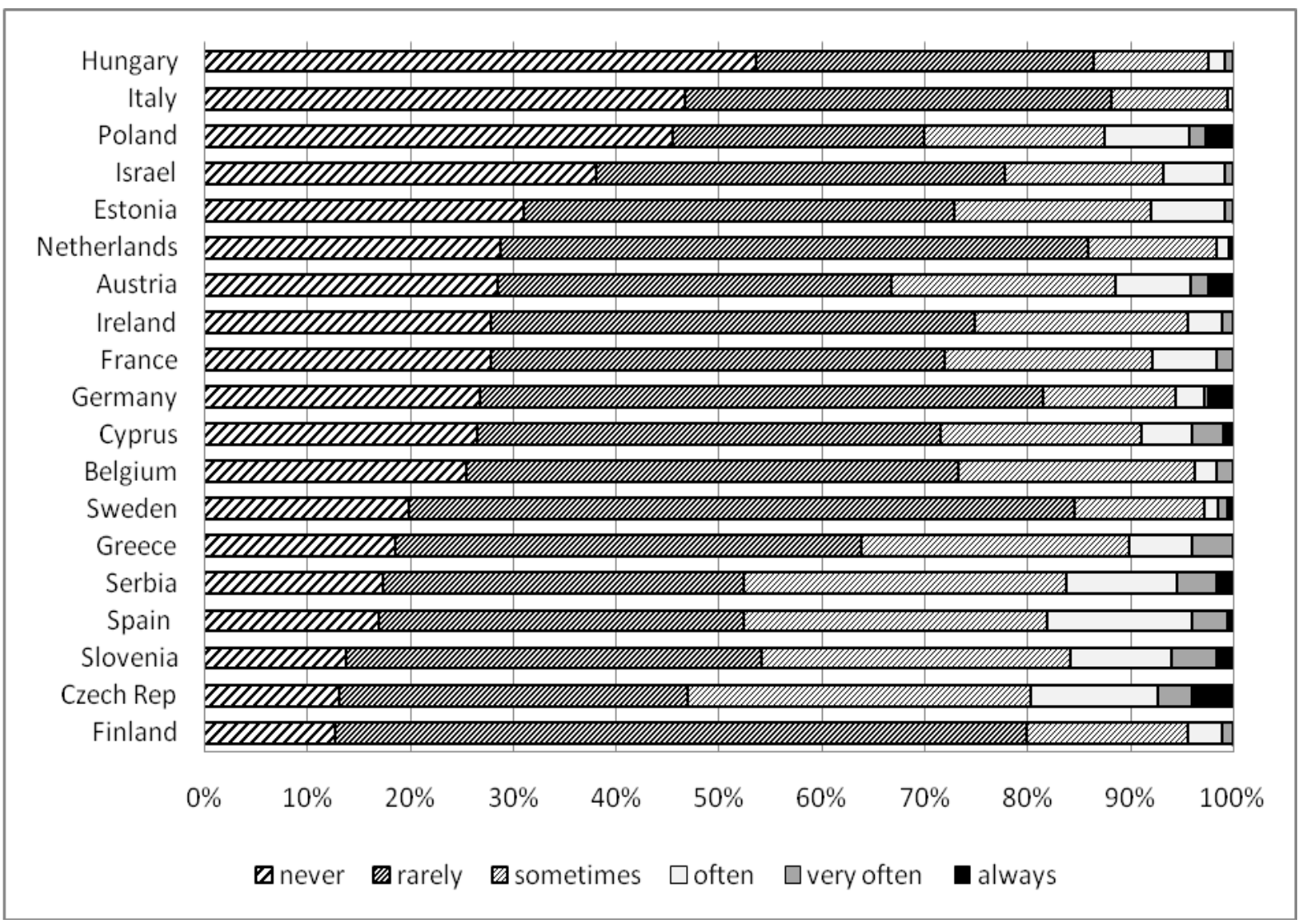

Figure 4: Perceived probability of being checked for alcohol, international comparison.

\section{CONCLUSION}

Behaviour, experience and attitudes of Czech drivers with respect to the issue of drinking and driving have evolved since the past SARTRE survey, reflecting attitudes to alcohol in the society, but also reflecting traffic safety activities in the past period.

To some extent, traditional negative attitude persists towards drinking and driving. Respondents generally disagreed with the statement "Most of your friends would drive under the influence of alcohol" - in an international comparison, the Czech Republic belongs to the countries with the lowest level of approval. As in previous surveys, they favoured more 
severe penalties for driving under the influence of alcohol, more often than before they consider the use of alcohol interlocks beneficial, they agree with the statements referring to the risks of driving under the influence of alcohol, and usually do not drive when having consumed alcohol.

Some results, however, point towards some easing opinions regarding alcohol and its maximum permitted levels in blood while driving a motor vehicle. The proportion of respondents who believe that they can drink a small amount of alcoholic beverages without getting over the legal limit of $0.0 \mathrm{~g} / \mathrm{l}$ increased and, particularly, there is rise in the percentage of drivers who would welcome a limit increase. This development is in direct conflict with the European trend of reducing the maximum permitted level of alcohol, which is clearly also accepted by the general public in European countries - in international comparison, the Czech sample has the largest proportion of those who wish that the limit was increased. Some indication of changes can also be observed when comparing certain attitudes (not behaviour) in the age groups of the youngest and the oldest drivers - the younger ones admit that their friends drive under the influence of alcohol, which is absolutely denied by the older group.

A significant change is apparent in the experience of the respondents with police checks for alcohol. The proportion of those who have not experienced any check over the past three years significantly decreased, and in an international comparison, the Czech Republic ranges among the countries with the lowest proportion of such drivers. This is reflected in the rise of the perceived probability of being checked - drivers now consider the probability of being checked higher than before.

\section{REFERENCES}

Baum, S., 2000. Drink driving as a social problem: comparing the attitudes and knowledge of drink driving offenders and the general community. Accident Analysis and Prevention, 32 (5), pp. 689-694.

Cauzard, J.-P., (ed.) et al., 1998. The attitude and behaviour of European car drivers to road safety. SARTRE 2 reports. Den Haag: SWOV.

Cauzard, J.-P. (ed.) et SARTRE consortium, 2004. European drivers and road risk. SARTRE 3 reports. INRETS.

Cestac, J., Delhomme, P. (eds.) et al., 2012. European road users' risk perception and mobility. The SARTRE 4 survey.

Greenberg, M. D., Morral, A. R., Jain, A. K., 2005. Drink-driving and DUI Recidivists' Attitudes and Beliefs: A Longitudinal Analysis. Journal of Studies on Alcohol, 66 (5), pp. 640-647.

Jornet-Gibert, M., Gallardo-Pujol, D., Suso, C., Andrés-Pueyo, A., 2013. Attitudes do matter: The role of attitudes and personality in DUI offenders. Accident Analysis \& Prevention, 50, pp. 445-450.

Shepherd, J. L., Lane, D. J., Tapscott, R. L., Gentile, D. A., 2011. Susceptible to Social Influence: Risky "Driving” in Response to Peer Pressure. Journal of Applied Social Psychology, 41 (4), pp. 773-797. 
Skládaná, P. et al., 2005. SARTRE 3 v České republice. Postoje řidičů k bezpečnosti silničního provozu. Brno (Czech Republic): Transport Research Centre (in Czech)

Stanojević, P., Jovanović, D., Lajunen, T., 2013. Influence of traffic enforcement on the attitudes and behavior of drivers. Accident Analysis \& Prevention, 52, pp. 29-38.

Vardaki, S., Yannis, G. 2013. Investigating the self-reported behavior of drivers and their attitudes to traffic violations. Journal of Safety Research, 46, pp. 1-11.

The article was produced under the support of the project

Transport R\&D Centre (CZ.1.05/2.1.00/03.0064) 